\title{
Clinical significance of additional gastrectomy after non-curative endoscopic submucosal dissection for early gastric cancer: a retrospective single-center study
}

\author{
Uicheon Jeong, Ho Yoon Bang, Pyeong Su Kim \\ Department of Surgery, Konkuk University Medical Center, Seoul, Korea
}

\begin{abstract}
Purpose: Additional surgery is recommended for patients after a non-curative endoscopic submucosal dissection (ESD) to prevent residual cancer (RC) or lymph node metastasis (LNM). We aimed to evaluate the clinicopathologic characteristics of patients who underwent an additional gastrectomy after a non-curative ESD procedure and identify the risk factors of RC and LNM.

Methods: We retrospectively assessed the clinicopathological factors of 73 patients who underwent additional gastrectomy following a non-curative ESD between January 2009 and December 2019 at our center.

Results: RC and LNM rates after additional gastrectomy were $9.6 \%$ and $8.2 \%$, respectively. Invasion deeper than $500 \mu \mathrm{m}(\mathrm{P}=0.045)$, positive horizontal resection margin $(P<0.001)$, and positive ESD margin $(P=0.001)$ were identified as statistically significant factors in univariate analysis for $\mathrm{RC}$, but not in multivariate analysis. Lymphatic invasion was the only risk factor found to be significant in both univariate and multivariate analyses $(\mathrm{P}=0.005$ and $\mathrm{P}=0.012)$.

Conclusion: Additional gastrectomy is necessary to prevent RC or LNM after non-curative ESD. Lymphatic invasion was also associated with LNM in patients who underwent an additional gastrectomy after a non-curative ESD, and in such cases, active treatment is required.
\end{abstract}

Keywords: Endoscopic submucosal dissection, Gastric cancer, Lymph node metastasis, Gastrectomy, Residual cancer

\section{INTRODUCTION}

Gastric cancer is the most common cancer and the fourth leading cause of cancer-related deaths in South Korea [1]. Early gastric cancer (EGC) is defined as adenocarcinoma confined to the mucosa or submucosa of the stomach with or without regional lymph node metastasis (LNM), and the prognosis is excellent even in the

Received: Aug 31, 2021 Accepted: Nov 12, 2021

Correspondence to: Pyeong Su Kim

Department of Surgery, Konkuk University Medical Center, 120-1

Neungdong-ro, Gwangjin-gu, Seoul 05030, Korea

Tel: +82-2-2030-7340, Fax: +82-2-2030-5209

E-mail: $20170121 @$ kuh.ac.kr

ORCID: Uicheon Jeong (https://orcid.org/0000-0003-0513-9020), Ho Yoon Bang (https://orcid.org/0000-0002-7164-3877), Pyeong Su Kim (https://orcid.org/00000002-1143-6278)

Copyright (C) 2021 Korean Society of Surgical Oncology

This is an Open Access article distributed under the terms of the Creative Commons Attribution Non-Commercial License (http://creativecommons.org/licenses/by-nc/4.0) which permits unrestricted non-commercial use, distribution, and reproduction in any medium, provided the original work is properly cited. presence of LNM [2].

The standard treatment option for gastric cancer is gastrectomy with regional lymph node dissection. However, in Korea and Japan, endoscopic submucosal dissection (ESD) has been accepted as an optional treatment for EGC without LNM [3]. The absolute indication for ESD as recommended by the Japanese gastric cancer treatment guidelines 2014 (4th edition) includes a differentiated type of adenocarcinoma without ulceration, the depth of invasion of which is clinical Tla and the diameter is $\leq 2 \mathrm{~cm}$ [4].

For patients who underwent non-curative ESD, additional surgery is recommended to prevent residual cancer (RC) or LNM. Non-curative factors include submucosal invasion (SM1) $>500 \mu \mathrm{m}$, lymphovascular invasion, undifferentiated histology, large tumor size, and a positive resection margin [5].

In this study, we aimed to evaluate the clinicopathological characteristics of patients who underwent an additional gastrectomy after a non-curative ESD procedure to identify the risk factors of RC and LNM. 


\section{METHODS}

\section{Patients}

We retrospectively reviewed 73 patients who underwent additional gastrectomy after non-curative ESD procedures between January 2009 and December 2019 at our center. The indication for ESD was decided according to the recommendations laid out by the Korean Practice Guidelines for Gastric Cancer (2018) for endoscopic resection [6]. Additional gastrectomy after ESD was performed in cases in which the pathologic result was beyond the criteria of curative resection, lymphatic invasion, or positive resection margins.

The study was approved by the Institutional Review Board of Konkuk University Medical Center (IRB No. KUMC 2021-09002) and performed in accordance with the principles of the Declaration of Helsinki. The informed consent was waived because this study design is a retrospective review.

\section{Procedure}

Additional gastrectomy was performed on 73 patients with D1+ lymph node dissection after non-curative ESD.

\section{Definitions}

Criteria for curative resection was defined according to the following four grades: (1) differentiated (well or moderately differentiated tubular or papillary) mucosal cancer measuring $>2 \mathrm{~cm}$ in the long diameter without ulcer (active or scar); (2) differentiated mucosal cancer measuring $<3 \mathrm{~cm}$ with ulcer; (3) undifferentiated mucosal cancer measuring $<3 \mathrm{~cm}$ without ulcer; or (4) differentiated submucosal cancer measuring $<3 \mathrm{~cm}$ with subtle submucosal invasion $(<500 \mu \mathrm{m})$.

\section{Statistical analysis}

IBM SPSS Statistics version 17 (SPSS Inc., Chicago, IL, USA) was used for statistical analysis. For categorical variables, the chi-square test or Fisher exact test was used. Based on this, a univariate analysis was performed. Multivariate logistic regression analysis was used to identify risk factors for RC and LNM, and a $\mathrm{P}<0.05$ was considered statistically significant.

\section{RESULTS}

\section{Clinicopathological characteristics}

During the study period, 73 patients (mean age, $62.2 \pm 9.9$ years) underwent additional gastrectomy after non-curative ESD for EGC. The tumor size was $2.1 \mathrm{~cm}$ (range, $0.5-5.7 \mathrm{~cm}$ ) and $16.4 \%$ of that exceeded $3 \mathrm{~cm}$ (Table 1). The reasons for additional gastrecto-
Table 1. Clinicopathologic characteristics

\begin{tabular}{|c|c|}
\hline Characteristic & Value $(n=73)$ \\
\hline Age (yr) & $62.2 \pm 9.9(31-77)$ \\
\hline \multicolumn{2}{|l|}{ Sex } \\
\hline Male & $54(74.0)$ \\
\hline Female & $19(26.0)$ \\
\hline \multicolumn{2}{|l|}{ Location of tumor } \\
\hline Upper & $8(11.0)$ \\
\hline Middle & $17(23.3)$ \\
\hline Lower & $48(65.7)$ \\
\hline \multicolumn{2}{|l|}{ Tumor type } \\
\hline Elevated & $23(31.5)$ \\
\hline Flat & $14(19.2)$ \\
\hline Depressed & $36(49.3)$ \\
\hline \multicolumn{2}{|l|}{ Type of surgery } \\
\hline Distal gastrectomy & 59 (70.9) \\
\hline Pylorus preserving gastrectomy & $1(1.4)$ \\
\hline Total gastrectomy & $13(17.8)$ \\
\hline Tumor size (cm) & $2.1 \pm 1.1(0.5-5.7)$ \\
\hline$<2$ & $41(56.2)$ \\
\hline 2 to $<3$ & $20(27.4)$ \\
\hline$\geq 3$ & $12(16.4)$ \\
\hline \multicolumn{2}{|l|}{ Depth of tumor } \\
\hline Mucosa & $20(27.4)$ \\
\hline SM1 & $14(19.2)$ \\
\hline$\geq \mathrm{SM} 2$ & $39(53.4)$ \\
\hline \multicolumn{2}{|l|}{ Tumor differentiation } \\
\hline Differentiated type & $55(75.3)$ \\
\hline Undifferentiated type & $18(24.7)$ \\
\hline Ulceration & $43(58.9)$ \\
\hline Resection margin positive & $30(41.1)$ \\
\hline Horizontal margin positive & $16(21.9)$ \\
\hline Vertical margin positive & $16(21.9)$ \\
\hline Lymphatic invasion & $20(27.4)$ \\
\hline
\end{tabular}

Values are presented mean \pm standard deviation (range) or number (\%). SM, submucosa.

my included submucosal invasion deeper than SM2 in 39 cases, ulceration in 43 cases, undifferentiated type in 18 cases, positive margin in 30 cases (horizontal 16 and vertical 16), and lymphatic invasion in 20 cases.

\section{Characteristics of cases with or without RC}

The clinicopathological features of the patients with or without RC after additional gastrectomy are shown in Table 2. RC was detected in $9.6 \%$ of the cases $(7 / 73)$. The ESD margin included horizontal and vertical resection margins. Univariate analysis determined that invasion deeper than SM2 $(\mathrm{P}=0.045)$, horizontal resection margin positivity $(\mathrm{P}<0.001)$, and ESD margin positivity $(\mathrm{P}=0.001)$ were 
Table 2. Characteristics of cases with and without residual cancer

\begin{tabular}{|c|c|c|c|}
\hline \multirow{2}{*}{ Characteristic } & \multicolumn{2}{|c|}{ Residual cancer, No. (\%) } & \multirow{2}{*}{ P-value } \\
\hline & Yes $(n=7)$ & No $(n=66)$ & \\
\hline Age & & & 0.430 \\
\hline$<65 \mathrm{yr}$ & $5(13.5)$ & $32(86.5)$ & \\
\hline$\geq 65 \mathrm{yr}$ & $2(5.6)$ & $34(94.4)$ & \\
\hline Sex & & & 0.668 \\
\hline Male & $6(11.1)$ & $48(88.9)$ & \\
\hline Female & $1(5.3)$ & $18(94.7)$ & \\
\hline Location of tumor & & & 0.720 \\
\hline Upper & $1(12.5)$ & $7(87.5)$ & \\
\hline Middle & $2(12.5)$ & 16 (87.5) & \\
\hline Lower & $4(8.3)$ & $43(91.7)$ & \\
\hline Tumor size & & & 0.124 \\
\hline$<3 \mathrm{~cm}$ & $4(6.8)$ & 55 (93.2) & \\
\hline$\geq 3 \mathrm{~cm}$ & $3(21.4)$ & $11(78.6)$ & \\
\hline Depth & & & 0.045 \\
\hline$<\mathrm{SM} 2$ & $6(17.6)$ & $28(82.4)$ & \\
\hline$\geq \mathrm{SM} 2$ & $1(2.6)$ & 38 (97.4) & \\
\hline Differentiation & & & 0.673 \\
\hline Differentiated & $6(10.9)$ & 49 (89.1) & \\
\hline Undifferentiated & $1(5.6)$ & $17(94.4)$ & \\
\hline Macroscopic type & & & 0.430 \\
\hline Non-depressed & $5(13.5)$ & $32(86.5)$ & \\
\hline Depressed & $2(5.6)$ & $34(94.4)$ & \\
\hline Vertical margin & & & 1.000 \\
\hline Positive & $1(6.2)$ & 15 (93.8) & \\
\hline Negative & $6(10.7)$ & 51 (89.3) & \\
\hline Horizontal margin & & & $<0.001$ \\
\hline Positive & $7(43.8)$ & $9(56.2)$ & \\
\hline Negative & 0 & $57(100)$ & \\
\hline ESD margin & & & 0.001 \\
\hline Positive & $7(23.3)$ & $23(76.7)$ & \\
\hline Negative & 0 & $43(100)$ & \\
\hline Ulceration & & & 0.435 \\
\hline Yes & $3(7.0)$ & 40 (93.0) & \\
\hline No & $4(13.3)$ & 26 (86.7) & \\
\hline Lymphatic invasion & & & 0.665 \\
\hline Yes & $1(5.0)$ & 19 (95.0) & \\
\hline No & $6(11.3)$ & 47 (88.7) & \\
\hline
\end{tabular}

SM, submucosa; ESD, endoscopic submucosal dissection.

significant factors for RC. However, multivariate logistic regression analysis did not identify these as being statistically significant factors.

\section{Characteristics of cases with or without LNM}

The relationships between the clinicopathological characteristics and LNM after additional gastrectomy are summarized in Table 3.
Table 3. Characteristics of cases with and without lymph node metastasis

\begin{tabular}{|c|c|c|c|}
\hline \multirow{2}{*}{ Characteristic } & \multicolumn{2}{|c|}{ Lymph node metastasis, №. (\%) } & \multirow{2}{*}{ P-value } \\
\hline & Yes $(n=6)$ & No $(n=67)$ & \\
\hline Age & & & 0.107 \\
\hline$<65 \mathrm{yr}$ & $1(2.7)$ & $36(97.3)$ & \\
\hline$\geq 65 \mathrm{yr}$ & $5(13.9)$ & 31 (86.1) & \\
\hline Sex & & & 1.000 \\
\hline Male & $5(9.3)$ & 49 (91.7) & \\
\hline Female & $1(5.3)$ & $18(94.7)$ & \\
\hline Location of tumor & & & 0.527 \\
\hline Upper & $1(12.5)$ & $7(87.5)$ & \\
\hline Middle & $2(11.1)$ & $16(88.9)$ & \\
\hline Lower & $3(6.4)$ & 44 (93.6) & \\
\hline Tumor size & & & 0.080 \\
\hline$<3 \mathrm{~cm}$ & $3(5.1)$ & $56(94.9)$ & \\
\hline$\geq 3 \mathrm{~cm}$ & $3(21.4)$ & $11(78.6)$ & \\
\hline Depth & & & 0.206 \\
\hline$<\mathrm{SM} 2$ & $1(2.9)$ & 33 (97.1) & \\
\hline$\geq \mathrm{SM} 2$ & $5(12.8)$ & 34 (87.2) & \\
\hline Differentiation & & & 1.000 \\
\hline Differentiated & $5(9.1)$ & $50(90.9)$ & \\
\hline Undifferentiated & $1(5.6)$ & $17(94.4)$ & \\
\hline Macroscopic type & & & 0.674 \\
\hline Not-depressed & $4(10.8)$ & 33 (89.2) & \\
\hline Depressed & $2(5.6)$ & $34(94.4)$ & \\
\hline Vertical margin & & & 0.606 \\
\hline Positive & $2(12.5)$ & $14(87.5)$ & \\
\hline Negative & $4(7.0)$ & $53(93.0)$ & \\
\hline Horizontal margin & & & 0.328 \\
\hline Positive & 0 & $16(100)$ & \\
\hline Negative & $6(10.5)$ & $51(89.5)$ & \\
\hline ESD margin & & & 1.000 \\
\hline Yes & $2(6.7)$ & 28 (93.3) & \\
\hline No & 4 (9.3) & 39 (90.7) & \\
\hline Ulceration & & & 0.221 \\
\hline Yes & $2(4.7)$ & 41 (95.3) & \\
\hline No & $4(13.3)$ & 26 (86.7) & \\
\hline Lymphatic invasion & & & 0.005 \\
\hline Yes & $5(25.0)$ & $15(75.0)$ & \\
\hline No & $1(1.9)$ & $52(98.1)$ & \\
\hline
\end{tabular}

SM, submucosal; ESD, endoscopic submucosal dissection.

LNM was found in six of the 73 patients (8.2\%) who underwent additional gastrectomy. Lymphatic invasion was the only significant factor for $\mathrm{LNM}(\mathrm{P}=0.005)$, and logistic regression analysis showed statistical significance $(\mathrm{P}=0.012)$. However, cases with tumors $<3 \mathrm{~cm}$ were $5.1 \%$ and cases with tumors $\geq 3 \mathrm{~cm}$ were $21.4 \%$, tumor size was weakly associated with $\operatorname{LNM}(\mathrm{P}=0.080)$, but other factors were not statistically significant (Table 3 ). 


\section{DISCUSSION}

ESD is a minimally invasive procedure performed for the treatment of EGC. Compared to surgery, ESD can avoid side-effects such as appetite loss, dysphagia, eating restrictions, and anxiety [7]. However, Tanabe et al. [8] reported a local recurrence rate of $0.22 \%$ in the absolute indication group for ESD, and local recurrence and LNM rates were $1.26 \%$ and $0.14 \%$ in the expanded indication group. They mentioned that local recurrence can occur when curative resection is not achieved at the horizontal or vertical margin, and LNM is associated with the presence of risk factors such as submucosal microinvasion and lymphovascular invasion.

Toyokawa et al. [9] reported that among patients who underwent non-curative ESD without additional gastrectomy, the incidence rates of RC and LNM were 9\% and 9\%, respectively. Lymphovascular invasion and the presence of undifferentiated type tumors were identified as risk factors for LNM, and a positive horizontal margin was identified as a risk factor for RC. Choi et al. [10] reported recurrence in 15\% (3/20) of patients with SM2 gastric cancer who were followed up after ESD without surgery. In both studies, the authors strongly recommended additional gastrectomy for patients that underwent non-curative ESD.

In our study, the rate of RC was 9.6\% (7/73). The depth of invasion ( $\geq$ SM2), positive horizontal margin, and ESD margin were associated with $\mathrm{RC}$ in the univariate analysis $(\mathrm{P}=0.045, \mathrm{P}<0.001$, and $\mathrm{P}=0.001)$. However, these factors were not statistically significant in the multivariate analysis. In previous studies of patients who underwent additional gastrectomy after ESD, RC rates ranged from $7.7 \%$ to $22.2 \%$. Positive horizontal margin, positive vertical margin, ulceration, lymphatic invasion, and neural invasion were reported as risk factors for RC [11-14]. In our cases, RC did not exist in the negative horizontal margin. However, Park et al. [15] reported the possibility of remnant malignant cells remaining on the negative resection margin because the coagulated portion of the resection margin could not be assessed accurately. In addition, RC may be considered to be cancer cells that spilled out from the vessels due to vascular stasis [9].

LNM rates for patients who underwent additional gastrectomy after non-curative ESD ranged from $7.5 \%$ to $17.8 \%$ [12-14,16]. Depth of invasion, lymphatic invasion, vascular invasion, and differentiation were the associated risk factors for $\operatorname{LNM}[12,13,16]$. In our study, the LNM rate after additional gastrectomy was 8.2\% (6/73), and lymphatic invasion was the only risk factor for LNM $(\mathrm{P}=0.012)$. Yamao et al. [17] reported that lymphatic invasion is an independent risk factor for LNM. Furthermore, Kamata et al. [18] demonstrated that matrix metalloproteinase-1 secreted from gastric cancer cells plays an important role in LNM as a sequela of lymphatic invasion.

There are some limitations to our study. This study was conducted retrospectively at a single institution. Because the number of cases included in this study was small, the evidence regarding the risk factors identified in this study is insufficient. Further multicenter data and prospective studies will be able to validate our findings and establish the risk factors definitively.

In conclusion, additional gastrectomy is necessary to prevent RC or LNM after non-curative ESD. Lymphatic invasion was also associated with LNM in patients who underwent an additional gastrectomy after a non-curative ESD, and in such cases, active treatment is required.

\section{CONFLICT OF INTEREST}

No potential conflict of interest relevant to this article was reported.

\section{REFERENCES}

1. Hong S, Won YJ, Park YR, Jung KW, Kong HJ, Lee ES, et al. Cancer statistics in Korea: incidence, mortality, survival, and prevalence in 2017. Cancer Res Treat 2020;52:335-50.

2. Carter KJ, Schaffer HA, Ritchie WP Jr. Early gastric cancer. Ann Surg 1984;199:604-9.

3. Ryu SJ, Kim BW, Kim BG, Kim JH, Kim JS, Kim JI, et al. Endoscopic submucosal dissection versus surgical resection for early gastric cancer: a retrospective multicenter study on immediate and long-term outcome over 5 years. Surg Endosc 2016;30:5283-9.

4. Japanese Gastric Cancer Association. Japanese gastric cancer treatment guidelines 2014 (ver. 4). Gastric Cancer 2017;20:1-19.

5. Son SY, Park JY, Ryu KW, Eom BW, Yoon HM, Cho SJ, et al. The risk factors for lymph node metastasis in early gastric cancer patients who underwent endoscopic resection: is the minimal lymph node dissection applicable? A retrospective study. Surg Endosc 2013;27:3247-53.

6. Guideline Committee of the Korean Gastric Cancer Association (KGCA), Development Working Group \& Review Panel. Korean Practice Guideline for Gastric Cancer 2018: an evidence-based, multi-disciplinary approach. J Gastric Cancer 2019;19:1-48.

7. Kim YI, Kim YA, Kim CG, Ryu KW, Kim YW, Sim JA, et al. Serial intermediate-term quality of life comparison after endoscopic submucosal dissection versus surgery in early gastric cancer patients. Surg Endosc 2018;32:2114-22.

8. Tanabe S, Ishido K, Matsumoto T, Kosaka T, Oda I, Suzuki H, et al. Long-term outcomes of endoscopic submucosal dissection for early gastric cancer: a multicenter collaborative study. Gastric Cancer 2017;20(Suppl 1):45-52. 
9. Toyokawa T, Ohira M, Tanaka H, Minamino H, Sakurai K, Nagami Y, et al. Optimal management for patients not meeting the inclusion criteria after endoscopic submucosal dissection for gastric cancer. Surg Endosc 2016;30:2404-14.

10. Choi JY, Jeon SW, Cho KB, Park KS, Kim ES, Park CK, et al. Non-curative endoscopic resection does not always lead to grave outcomes in submucosal invasive early gastric cancer. Surg Endosc 2015;29:1842-9.

11. Katsube T, Murayama M, Yamaguchi K, Usuda A, Shimazaki A, Asaka $\mathrm{S}$, et al. Additional surgery after non-curative resection of ESD for early gastric cancer. Anticancer Res 2015;35:2969-74.

12. Ishida R, Kanaji S, Maehara R, Hasegawa H, Yamamoto M, Matsuda Y, et al. Significance of additional gastrectomy including endoscopic submucosal dissection scar for gastric cancer. Anticancer Res 2018;38:5289-94.

13. Sunagawa H, Kinoshita T, Kaito A, Shibasaki H, Kaneko K, Ochiai A, et al. Additional surgery for non-curative resection after endoscopic submucosal dissection for gastric cancer: a retrospective analysis of 200 cases. Surg Today 2017;47:202-9.
14. Tian YT, Ma FH, Wang GQ, Zhang YM, Dou LZ, Xie YB, et al. Additional laparoscopic gastrectomy after noncurative endoscopic submucosal dissection for early gastric cancer: a single-center experience. World J Gastroenterol 2019;25:3996-4006.

15. Park JC, Lee SK, Seo JH, Kim YJ, Chung H, Shin SK, et al. Predictive factors for local recurrence after endoscopic resection for early gastric cancer: long-term clinical outcome in a single-center experience. Surg Endosc 2010;24:2842-9.

16. Ren MH, Qi XS, Chu YN, Yu YN, Chen YQ, Zhang P, et al. Risk of lymph node metastasis and feasibility of endoscopic treatment in ulcerative early gastric cancer. Ann Surg Oncol 2021;28:2407-17.

17. Yamao T, Shirao K, Ono H, Kondo H, Saito D, Yamaguchi H, et al. Risk factors for lymph node metastasis from intramucosal gastric carcinoma. Cancer 1996;77:602-6.

18. Kamata I, Ishikawa Y, Akishima-Fukasawa Y, Ito K, Akasaka Y, Uzuki M, et al. Significance of lymphatic invasion and cancer invasion-related proteins on lymph node metastasis in gastric cancer. J Gastroenterol Hepatol 2009;24:1527-33. 